\title{
RETRAÇANDO A MEMÓRIA DA IMIGRAÇÃO POLONESA NO RS: UMA LEITURA DA OBRA DE LETÍCIA WIERZCHOWSKI A PARTIR DOS RASTROS
}

Tracing the Polish Immigration Memory in RS: Reading LETÍCIA WIERZCHOWSKI'S WORK FROM TRACES

\section{Zilá Bernd}

Universidade Federal do Rio Grande do Sul

Porto Alegre, RS, Brasil

\section{Resumo}

Análise dos romances Uma ponte para Terebin (2006), Os Getka (2010) e Cristal polonês (2003), da escritora gaúcha Letícia Wierzchowski (1972-), que se consagrou nacionalmente com a Casa das sete mulheres. Na esteira de Moacyr Scliar, com a imigração judaica, de Pozenato, com a imigração italiana ou Josué Guimarães, com a imigração alemã, a autora retraça a presença polonesa no sul do país a partir de fragmentos (resíduos) memoriais como cartas, fotografias, relatos orais, onde o tom é dado pela memória afetiva.

\begin{abstract}
Analysis of Letícia Wierzchowsky's novels: Uma ponte para Terebin (2006), Os Getka (2010) e Cristal polonês (2003). She is an author from the state of Rio Grande do Sul/ Brazil. This author wrote also The House of the Seven Women through which she became renowned. Following Moacyr Scliar, José Clemente Pozenato and Josué Guimarães in terms of Jewish, Italian and German immigration matters, respectively, the author retraces the Polish presence in the southern part of Brazil through memorial fragments (traces) such as letters, photos and oral narratives where the tone is gotten from the affective memory.
\end{abstract}

\section{Résumé}

Analyse des romans Uma ponte para Terebin (2006), Os Getka (2010) et Cristal polonês (2003), de l'écrivaine gaucha Letícia Wierzchowski (1972-), qui a conquis reconnaissance nationale avec Casa das sete mulheres. Dans le sillage de Moacyr Scliar, avec l'immigration juive, de José Clemente Pozenato, avec l'immigration italienne et Josué Guimarães, avec l'immigration allemande, l'auteure dessine la présence polonaise au sud du Brésil à partir de traces, vestiges (résidus) mémoriels comme les lettres, les vieilles photos, les récits oraux, où le diapason est donné par la mémoire affective.
Palavras-chave: Rastros, resíduos memoriais (traces), literatura migrante, Letícia Wierzchowski, romance memorial.
Keywords: Traces, Migrant literature, Letícia Wierzchowski, Memorial Novel (Roman mémoriel).

Mots-clés: Traces, résidus, vestiges mémoriels, littérature migrante, Letícia Wierzchowski, roman mémoriel. 
* (VIEIRA, Marta Lourenço. A metaforização da memória ou a Dialética da rememoração em Walter Benjamin. In: VIEIRA, Marta Lourenço; SILVA, Izabel de Oliveira (orgs.). Memória, subjetividade e educação. Belo Horizonte: Argumentum, 2007: 19-29.)
A memória não é, para Benjamin, simplesmente a faculdade de reter conhecimentos e fatos vividos no passado, mas a capacidade de reconhecer as impressóes deixadas por eles e (re)significá-las no presente, produzindo sobre elas um novo sentido e com elas estabelecendo uma nova relação.*

O presente artigo pretende estudar a memória da imigração polonesa no estado do Rio Grande do Sul, através da leitura da obra de Letícia Wierzchowski, ${ }^{1}$ que se tornou conhecida nacionalmente por $A$ casa das sete mulheres (Record, 2002), que virou série televisiva. Em Uma ponte para Terebin (Record, 2006), a autora retraça, através de rastros memoriais, a trajetória de seu avô, Jan Wierzchowski, da Polônia, onde nasceu, para o Brasil onde chegou na condição de imigrante, em 1936. Na esteira de autores como Moacyr Scliar, que retraçou a memória judaica no RS em numerosos romances, de José Clemente Pozenato, que se ocupou, em $O$ Quatrilho (1985), em narrar os primeiros anos da imigração italiana no sul do Brasil ou de Josué Guimarães, cujo foco foi a reconstituição da presença alemã em A ferro e fogo I (1972) e II (1975), Letícia Wierzchowski vem, com Uma ponte para Terebin, mas também com $O s$ Getka (Record, 2010) e Cristal polonês (Record, 2003), preencher uma lacuna na história da literatura do Rio Grande do Sul, buscando, através do exercício da memória, recuperar os vestígios da presença étnica e cultural de poloneses na região sul.

A imigração polonesa no Brasil inicia em 1841 e vai até 1971, sendo que cerca de $40 \%$ dos imigrantes destinaram-se ao Paraná e em torno de 38\% ao Rio Grande do Sul. A maioria era composta por imigrantes católicos, havendo alguns poloneses de crença judaica que se destinaram, sobretudo, a São Paulo. A obra de Letícia Wierzchowski é pioneira na tentativa de empreender a representação literária do percurso desse contingente migratório em nosso estado. Com base em fragmentos como velhas fotografias, cartas, um passaporte e outras lembranças encontradas em uma caixa na

\footnotetext{
${ }^{1}$ Letícia Wierzchowski, nascida em 1972, vive em Porto Alegre, onde escreve uma coluna semanal para o Jornal Zero Hora, além dos romances e obras de literatura infanto-juvenil. Suas obras já foram traduzidas para mais de 30 idiomas e somam um total de 19 romances. É casada e tem dois filhos pequenos. Ganhou notoriedade nacional com a versão televisiva da obra $A$ casa das sete mulheres. Atualmente trabalha no roteiro de uma versão para a TV da obra de Erico Verissimo, O tempo e o vento (1948), sob a direçẫo de Jayme Monjardim. (Cf. "Letícia conta Verissimo". Porto Alegre, Interview, n. 1, dez. 2011:36-45.)
} 
casa da mãe da autora, as peripécias do avô Jan Wierzchowski puderam ser tecidas, em um trabalho que envolveu também pesquisa documental (sobre a Segunda Guerra Mundial) e testemunhos de parentes e amigos. Assim a história de vida do avô e do soldado foi reconstruída a partir de rastros (traços), acionando a memória afetiva que levou em conta os afetos familiares e as sensibilidades.

Ao iniciar a análise da obra, cabe evocar alguns dos principais autores que nos legaram valiosos estudos sobre a memória (voluntária/involuntária, individual/coletiva) e, principalmente sobre o conceito de rastro, vestígio, resto (spur, em alemão; trace, em francês), que nos ajudaráo a perceber "a presença de uma ausência" no projeto biográfico (ou bioficcional) da autora.*

\section{Lendo Uma ponte para Terebin}

a partir dos vestígios/rastros memoriais

A erudita reflexão de Paul Ricoeur sobre rastros retoma a célebre metáfora platônica da marca de um sinete na cera quente. Depois de retirado o sinete, permanece apenas a marca, evocando a "presença de uma ausência". A rememoração é, portanto, tratada como um reconhecimento da impressão deixada pelo sinete. A partir dessa marca (traço) pode-se recuperar a forma, o peso e demais características do sinete. No mesmo trecho, cita Marc Bloch, para quem a história pretende ser "uma ciência dos rastros". ${ }^{*}$ Distingue três empregos da palavra "rastro" a fim de dissipar possíveis confusōes relativas a seu emprego: a) os rastros com os quais trabalha o historiador, ou seja, o rastro escrito num suporte material; b) a impressão enquanto afecção na alma (os afetos) e c) a impressão cerebral, cortical, que diz respeito à neurociência.

A romancista trabalharia, em princípio, seguindo a divisão acima, na confluência dos dois primeiros tipos de rastros tentando recuperar situaçóes da vida dos personagens a partir de resíduos que podem ser recuperados em documentos escritos e em detalhes inscritos nas cartas, nas fotografias e nos depoimentos familiares (orais), com base nos quais é possível reconstituir quadros sociais da memória em que seu avô se inseriu ao longo dos anos tanto na Polônia quanto no Brasil. A imaginação criadora da autora completará as lacunas do que foi ocultado ou apagado. Nesse sentido, a partir da memória individual, tenta recompor a memória coletiva da comunidade de pertença do personagem, rememorando e
* (RICOEUR, Paul. Platão: a representação presente de uma coisa ausente. In: A memória, a história, o esquecimento. Campinas: editora Unicamp, 2007: 27-39. Trad. Alain François et al.)

* (Ibidem: 32.) 
recompondo a coletânea de rastros deixados pelos acontecimentos vividos tanto no ambiente familiar, como escolar, social etc. No caso da reconstituição do itinerário do avô da Polônia para o Brasil e sua volta à Polônia para lutar na Segunda Guerra Mundial, é a partir da memória compartilhada pelos que estiveram próximos a ele e através das fotos e cartas que deixou que a narradora decifrará sua rotina e sua visão de mundo, na tentativa de reavaliar sua própria identidade como descendente de poloneses. Indícios, testemunhos e restos de lembranças ajudam-na a recompor a trajetória de Jan Wierzchowski, seu amor pelo Brasil, o aprendizado da língua portuguesa, a dureza da vida de imigrante e as agruras da guerra.

Para Ricoeur, o esquecimento pode significar o apagamento dos rastros, mas também sua permanência, uma vez que as marcas deixadas pelos afetos tendem a ser duradouras e podem aflorar ao consciente através de associações de ideias e da memória involuntária que se organiza no nível do subconsciente. Assim, a ilustração de capa de Uma ponte para Terebin - uma chávena de chá é a "ponte" que une o velho mundo (representado por uma mesa de estilo europeu) e o novo mundo (representado por uma mesa em estilo colonial) - poderia ser interpretada como uma alusão à xícara de chá de Em busca do tempo perdido, de Marcel Proust, da qual emergem cenas da infância do personagem marcadas por grande carga afetiva. A xícara de chá é de porcelana e, portanto, poderia remeter também à fragilidade dessa ponte que une e separa o país de origem do país de adoção do personagem. Na verdade, não é uma única ponte que liga e separa a Polônia do Brasil: são muitas as pontes construídas com os fios da rememoração ${ }^{2}$ que alimentam a escrita do romance. Em determinados capítulos, quando Jan está no front, a autora narra acontecimentos passados no Brasil e na Polônia, passando, de um parágrafo a outro, de cenas vividas por Jan na Europa a cenas vividas por Anna, sua esposa, em sua casa em Porto Alegre.

\footnotetext{
${ }^{2}$ Segundo Benjamin, em "O narrador: consideraçóes sobre a obra de Nikolai Leskov" (In: BENJAMIN, Walter. Magia e técnica, arte e política. Obras escolhidas, I. São Paulo: Brasiliense, 1985: 197-201), enquanto a memória é a musa da narrativa, sustentando a poesia épica, a rememoração é a musa do romance. Rememoração, do alemão Eingedenken, remete a ein (um) e gedenken (lembrar), referindo-se a lembrar de alguma coisa específica: de "um herói, uma peregrinação, um combate" (Cf. PORTUGAL, Ana Maria. O tesouro das lembranças vestígios. In: SELDMAYER, Sabrina; GINZBURG, Jaime (orgs.) Walter Benjamin: rastro, aura e história. Belo Horizonte: editora da UFMG, 2012: 196).
} 
Um estudo que tem por base os rastros e que não recuperasse os ensinamentos seminais de Walter Benjamin não estaria completo. Em muitos de seus textos ele retoma o conceito de rastro/ resto/detrito como essencial para a compreensão da modernidade e poder-se-ia dizer que o mesmo está disseminado em toda a sua obra, culminando em Passagens.* É, contudo, em «Sur quelques thèmes baudelairiens»* e "A Paris do segundo império em Baudelaire"* que podemos seguir melhor seu pensamento sobre o tema. Em "A Paris do segundo império em Baudelaire" (escrito entre abril de 1937 e setembro de 1938, logo poucos anos antes de sua morte), o autor parte do célebre poema do poeta francês - "Le vin des chiffoniers" - que recupera a figura do trapeiro, catador (chiffonier) que percorre as ruas de Paris atrás de detritos, de restos encontrados no lixo. Baudelaire identifica a sua função de poeta com a do catador: trapeiro ou poeta o lixo importa aos dois, já que o poeta - como o trapeiro - erra pela cidade à noite catando restos de rimas. Elementos do submundo e da marginalidade, fenômenos residuais e de decadência, são transformados em matéria da poesia, sendo, ao mesmo tempo, precursores de novos tempos e instrumentos para entender o passado.

Em texto recente, Jaime Ginzburg* ressalta a atualidade do pensamento de Benjamin acerca dos rastros, conceito que se constitui, segundo o autor, em "uma contribuição produtiva para as ciências humanas".* O pesquisador da USP alerta para a importância do papel do leitor na valorização do resíduo: ele tem que ser capaz de agir como um detetive, atento à potencialidade significativa do dito e do que foi silenciado.

O interesse de Benjamin pela fotografia* está em certa medida associado à questão do resíduo, pois a fotografia capta uma imagem em um determinado período da vida de uma pessoa ou grupo, podendo ser interpretada também como rastro, como captação do efêmero, que permite ao observador, anos mais tarde, a partir de um pequeno detalhe (um sorriso ou um olhar) recompor um traço da personalidade do fotografado ou um episódio marcante de sua trajetória. Permanece como "impressão", marca do vivido.

Uma ponte para Terebin é, como refere sua autora, "a história de uma caixa de retratos que um dia começou a falar".* Em habilidosa estratégia narrativa, a autora cede a voz narrativa às figuras das fotos: temos assim, no capítulo 13, "A velha na fotografia", a voz da bisavó; enquanto no 35, a voz narradora é a do bisavô ("O
* (BENJAMIN, Walter. Passagens. Belo Horizonte: editora da UFMG; São Paulo: Imprensa oficial do Estado, 2006. Ed. Org. por Willi Bolle.)

* (In: BENJAMIN, Walter. Charles Baudelaire; un poète lyrique à l'apogée du capitalisme. Paris: Payot, 2002: 147-207.)

* (In: KOTHE, F. (org.) Walter Benjamin - Sociologia. São Paulo: Ática, 1985: 44-122.)

* (GINZBURG, Jaime. "A interpretação do rastro em Walter Benjamin". In: SEDLMAYER, Sabrina; GINZBURG, Jaime (orgs). Walter Benjamin; rastro, aura e história. Belo Horizonte: Editora da UFMG, 2012: 107-132.)

* (Ibidem: 107.)

* (BENJAMIN, Walter. "Pequena história da fotografia". In: KOTHE, F. (org.) Walter Benjamin - Sociologia. São Paulo: Atica, 1985: 219-240.)

*(WIERZCHOWSKI, Letícia. Texto de orelha. In: Uma ponte para Terebin. Rio de Janeiro: Record, 2006.) 
* (WIERZCHOWSKI, Letícia. Uma ponte para Terebin. Rio de Janeiro: Record, 2006: 102.)

* (In: GAGNEBIN, Jeanne Marie. Lembrar escrever esquecer. São Paulo: Editora 34, 2009, 2. ed.: 107-118.)

* (In: SELDMAYER, Sabrina; GINZBURG, Jaime (orgs.) op.cit.: 27-38.)

* (VERNANT, J.-P. L'individu, la mort, l'amour. Paris: Gallimard, 1989: 70-73.) velho na fotografia") e assim sucessivamente. Tal estratégia agrega à narrativa de 444 páginas dinamismo e vivacidade. As fotos, elementos residuais, se sobrepóem ao esquecimento e a outros agentes de destruição como o esmaecimento e até o apagamento de imagens, comuns em fotografias antigas.

Não haveremos de deixar mais do que isso. Rastros. Papéis amarelados que o tempo e o desleixo haverão de consumir. Fotografias que já perderam o brilho. Esgotado o sentimento. O que sobra? Por isso caminho pela vida de Jan e de Anna com tanto cuidado. E assim imagino-os naqueles anos tão inseguros... Imagino-os sentados na sala na noite quieta. Esperando.*

$\mathrm{O}$ achado das fotos e o desejo da autora de querer ouvir as falas das figuras aí retratadas estabelece uma conexão entre passado e presente que não a levam a totalizaçóes conclusivas, mas a colocam diante de incertezas em relação à trajetória do avô, devido à existência de determinadas fases que lhe foram impossíveis de recompor. Contudo, seguir os rastros, as pistas deixadas pelas fotos e pelas cartas fazem não apenas com que a figura do avô seja lembrada como a de toda a comunidade na qual ele estava inserido onde muitos tomaram a mesma decisáo de regressar à Polônia para combater pela liberdade.

Outra fonte indispensável de ser consultada, quando se trata de entender a questão dos rastros, são as obras da professora e pesquisadora da Unicamp e da PUC-SP, Jeanne Marie Gagnebin, estudiosa de Walter Benjamin e em particular da questáo dos rastros e restos. Lembramos em particular, no âmbito do presente artigo, seu ensaio "O rastro e a cicatriz: metáforas da memória", ${ }^{*}$ bem como a retomada desse ensaio para o coletivo organizado por J. Ginzburg e S. Seldmayer: "Apagar os rastros, recolher os restos".*

Em ambos os ensaios, Gagnebin relembra, na esteira de Jean-Pierre Vernant, ${ }^{*}$ que a etimologia de vestígio ou rastro é sema que significa igualmente signo, mas originariamente referia-se a túmulo. A luta dos heróis gregos por serem enterrados e terem um túmulo significava uma luta contra o esquecimento. Não podia haver castigo mais cruel do que deixar um corpo insepulto, porque, sem túmulo, desapareceriam os últimos vestígios da passagem de uma pessoa na terra.

A autora lembra ainda um ponto crucial no que se poderia chamar de uma "teoria dos rastros" - embora Benjamin detestasse as totalizaçôes -: que os restos/detritos não são intencionais 
do sujeito, são aquilo que "escapa ao controle da consciência em Freud e da memória voluntária em Proust; rastros involuntários ou inconscientes de algo que não está explícito". * Contudo, para Benjamin o rastro não tem a mesma importância que tinha para Freud, cuja teoria recolhe os detalhes do subconsciente para chegar à interpretação e à cura, nem para o detetive para quem a observação das pistas deixadas pelo criminoso servem para levar à elucidaçấo do crime. Para Benjamin, a importância de rastros, insignificantes para a maioria, pode levar à valorização de pessoas de menor importância na escala social sobre as quais não há registros historiográficos, iluminando, assim, a partir de outro ponto de vista, aspectos da história descurados pelas elites dominantes.

Essa possibilidade de resgatar elementos que a historiografia oficial deixou de lado é, na verdade, a grande importância do estudo dos rastros e que levou Benjamin a voltar a eles em muitos momentos de sua obra. O esforço de Letícia Wierzchowski em não permitir que os rastros do avô, um cidadão comum, um imigrante pobre, sejam apagados, está exatamente dentro da perspectiva benjaminiana de preservar os detalhes que nos permitem hoje vislumbrar não apenas a vida de um imigrante polonês, mas o papel que representaram esses estrangeiros recém-chegados ao Novo Mundo. É a valorização da micro-história como contraponto à História oficial preocupada apenas em glorificar os feitos das camadas dominantes de uma época. Sabemos que, muitas vezes, é o que está na margem, naquilo com quem ninguém se preocupa e que foi relegado ao esquecimento, que podem estar elementos reveladores para a história cultural e/ou para uma história das sensibilidades.

Outro autor cujo nome é frequentemente associado à questâo dos rastros é Carlo Ginzburg. Em "Raízes de um paradigma indiciário",* o autor compara curiosamente Morelli, Sherlock Holmes e Freud, todos interessados em examinar os pormenores mais negligenciados, baseando suas análises em índices imperceptíveis. Giovanni Morelli era reconhecido especialista em artes plásticas, capaz de reconhecer imitaçóes tidas como perfeitas. Em que se baseava o "método morelliano" do qual os historiadores da arte falam ainda hoje? Não era pelos grandes traços que ele descobria as falsificações, mas por ínfimos pormenores como os lóbulos de orelhas, os dedos dos pés, o formato das unhas. O método indiciário de Morelli foi comparado ao do famoso personagem de Arthur Conan Doyle, Sherlock Holmes, detetive capaz de decifrar crimes
* (GAGNEBIN, J.-.M, op. cit. 2012: 32.)

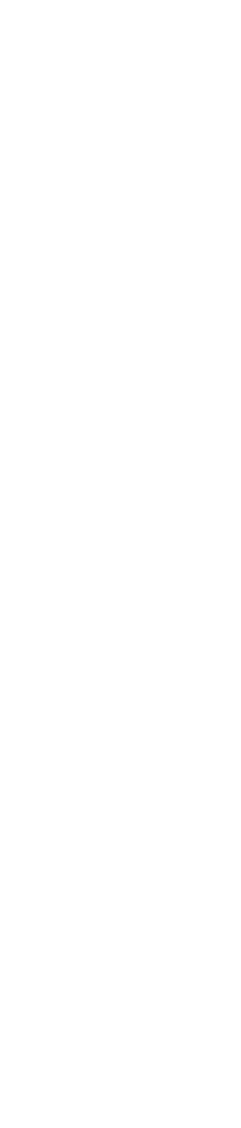

* (In: GINZBURG, Carlo. Mitos, emblemas, sinais; morfologia e história. São Paulo: Companhia das Letras, 2011: 143-180. 2. ed.. 4. reimpressão. Trad. Frederico Carotti.) 
* (FREUD, Sigmund. O Moisés de Michelangelo, 1914, citado por GINZBURG, op. cit.: 147.$)$

*(GINZBURG, op.cit.: 150.)

* (GINZBURG, Jaime, op. cit., 2012: 115.) baseado em indícios imperceptíveis para a maioria, como pegadas na lama, cinzas de cigarro, etc. Os escritos de Morelli (pseudônimo de Ivan Lermoliev) interessaram Sigmund Freud, que julgou seu método estreitamente aparentado à técnica da psicanálise: "Esta também tem por hábito penetrar em coisas concretas e ocultas através de elementos pouco notados ou desapercebidos, dos detritos ou refugos da nossa observação".* Segundo Ginzburg, o que interessou ao jovem doutor Freud nos estudos de Morelli foi "a proposta de um método interpretativo centrado sobre os resíduos, sobre os dados marginais, considerados reveladores. Desse modo, pormenores, considerados sem importância ou até triviais, 'baixos', forneciam a chave para aceder aos produtos mais elevados do espírito humano".* As pistas infinitesimais eram, para Freud, sintomas, para Sherlock Holmes, indícios, e, para Morelli, signos pictóricos.

O longo artigo de Ginzburg é muito interessante, mas não nos cabe aqui referi-lo na íntegra. Restringimo-nos a apontar a enorme repercussão que teve, sendo citado inclusive por Paul Ricoeur, em A história, a memória, o esquecimento, entre outros como Jeanne Marie Gagnebin e Jaime Ginzburg. Como acabamos de mencionar acima, é importante distinguir o interesse pelos indícios e pormenores por Freud, Morelli ou Sherlock Holmes do interesse de Benjamin, que conferia ao detalhe, ao resto "um papel constitutivo do passado".*

Para fins da análise dos três romances de Letícia Wierzchowski, o pensamento de Benjamin nos parece o mais fértil, pois sua reflexão sobre os rastros é muito oportuna por se contrapor a políticas de esquecimento. Assim, o filósofo autor de Passagens nos alerta em relação ao apagamento dos rastros e ao potencial de conhecimentos do passado que a atençáo aos rastros, vestígios e fragmentos pode trazer.

Ao se propor a redigir uma biografia ficcional do avô, a intenção é não deixar que os rastros memoriais de sua família se apaguem. Sabedora de que memória e esquecimento são duas faces da mesma moeda, sabe que seu texto conterá opacidades e incertezas, zonas de sombra e zonas em que os fatos são reconstituídos com clareza. O importante é entender o passado familiar através da construção do romance memorial, que é definido por Régine Robin como o romance

através do qual um indivíduo, um grupo ou uma sociedade pensa seu passado modificando-o, deslocando-o, deformando-o, inventando 
lembranças, um passado glorioso, ancestrais, afiliaçóes, genealogias, ou ao contrário, lutando pela exatidão factual, para propiciar a reconstituição do acontecimento ou sua ressurreição.*

Para refazer a dupla história do avô e do soldado que não hesitou em deixar mulher e filho no Brasil para lutar pela liberdade de seu país de origem, foi necessário que a autora construísse uma ponte. Entre memória, esquecimento e imaginação foi construída a ponte que lhe permitiu narrar uma primeira travessia do Atlântico - uma travessia que pretendeu ser sem volta, já que emigrar é uma decisão irreversível - e uma segunda travessia do Brasil para a Europa para unir-se às forças aliadas na luta contra o nazismo. Jan Wierzchowski permaneceu dois longos anos longe da família, durante os quais escreveu muitas cartas, algumas transcritas quase na íntegra pela autora. A volta de Jan ao Brasil - sua terceira travessia do Atlântico - será definitiva.

Há que se louvar o generoso gesto de Letícia Wierzchowski de recolher os rastros da história de vida do avô e, em consequência, iluminar, pela via do romance memorial, a táo esquecida participação dos poloneses na constituição da identidade sul-rio-grandense. O que se lê não é a história oficial cheia de lacunas quanto ao desamparo com que o governo brasileiro relegou os imigrantes, mas a memória recuperada de fragmentos que relembram aspectos que não constam de documentos oficiais ou manuais escolares como o fato de as famílias dos imigrantes que foram combater na Europa nunca terem recebido o soldo do trabalho de seus maridos que arriscavam a vida no front. A narradora relembra a penúria das esposas que mal falavam a língua portuguesa e que tiveram que improvisar ofícios como o de costureira para poder alimentar os filhos.

Letícia Wierzchowski deixa com esse romance um rastro: o rastro privilegiado da escritura, que é, no dizer de Jeanne Marie Gagnebin, o rastro de si mesmo. A reminiscência revela de forma fragmentada e não oficial, verdades que foram escamoteadas, rasuradas até caírem no esquecimento. Como a memória, o rastro também é um processo sempre inacabado, é algo que se constrói e se desconstrói no percurso de sua elaboração. Entre memória e esquecimento (que não são termos antitéticos, mas complementares), encontram-se os rastros, os detritos, os vestígios. A autora explica em várias passagens da obra a origem dessa busca incessante de entender o passado de sua família:
* (ROBIN, Régine. Le Roman mémoriel. Montreal: Le Préambule, 1989: 48.) 
* (WIERZCHOWSKI, L., op. cit., 2006: 131.)

* (BENJAMIN, Walter. Escavando e recordando. In:__ Rua de mão única. Obras escolhidas. Vol. II. São Paulo: Brasiliense, 1998:239.)

*(WIERZCHOWSKI, Letícia. Cristal polonês. São Paulo: Record, 2003: 88.)
Então é disso que eu trato aqui, da memória das coisas vividas há tantos anos - da sua vida, Jan, e dos vestígios que dela me ficaram. Como essa fotografia, por exemplo.*

O ganho de escavar o passado não é o de encontrar soluçóes ou respostas definitivas; é o processo em si de escavar que atua como questionamento identitário. No dizer de Benjamin: "Quem pretende se aproximar do próprio passado soterrado deve agir como um homem que escava".*

\section{Lendo Cristal polonês e Os Getka}

Logo após a publicação de $A$ casa das sete mulheres, obra traduzida em várias línguas, Letícia, que havia focalizado nesse romance fatos da história do Rio Grande do Sul, narrando-os de uma perspectiva diferente da usual, ou seja, do ponto de vista das mulheres que ficaram à espera dos pais, amantes e maridos que partiram para a longa e sangrenta Revolução Farroupilha, também chamada Guerra dos Farrapos (1835-1845), traz a lume o delicado e breve romance Cristal polonês.

Trata-se de um mergulho nas agruras da família Lovanski, de origem polonesa. Pode ser considerado como uma preparação para empreender o complexo romance Uma ponte para Terebin, que envolveu detalhada pesquisa histórica sobre os últimos dois anos da Segunda Guerra Mundial. Alguns temas presentes em Cristal polonês serão retomados anos mais tarde em Uma ponte para Terebin, como a participação ativa da mulher em exercer a atividade de costureira para completar o miserável salário do marido imigrante e a dolorosa perda do filho. Em Cristal polonês, é o menino Miti de seis anos de idade que mergulha em um lago gelado, de onde não voltará com vida: "o menino que queria desvendar o sono do lago, e que queria conhecê-lo inteiro por dentro e por fora. Um dia. Quando estivesse sozinho".* Em Uma ponte para Terebin, Anna, a mulher de Jan, perde o filho Janeczek ainda garoto com câncer enquanto o marido lutava na guerra no velho mundo. Ambos os romances focalizam o sofrimento das mulheres com a morte de filhos pequenos e o trabalho do luto que realizam estoicamente. Em ambos, as temáticas recorrentes são a perda, o luto e o fato de as mulheres assumirem o papel de esteio da família.

Em Os Getka, último romance publicado pela autora, o tema da perda sem reparação volta de modo contundente através da 
narrativa da morte de Lylia Getka, a mulher amada pelo narrador Andrzej. O livro inicia com o narrador em busca de um tema para um novo livro e é nesse momento que ele empreende uma volta ao passado para rememorar a época em que conheceu Lylia, filha também de pais poloneses.

Como nos outros dois romances, Os Getka inicia com o relato da angústia do narrador ao escavar as memórias desse tempo já distante:

A única coisa que posso fazer, a única coisa que me permito fazer, é recordar. Porém, tudo agora me soa táo distante que é como se jamais tivesse existido.

$\mathrm{Na}$ verdade, o passado de todos os homens parece uma espécie de mentira... Quem jamais poderá provar a veracidade daquilo que ficou prá trás? Por isso, talvez, fazemos diários, tiramos fotografias, guardamos velhos impressos de teatro e gastas passagens de algum trem europeu onde um dia passamos uma tarde de nossas vidas. Imagens, borróes de tinta, peças de roupa, cartóes postais apagados, recortes de jornal, mechas de cabelo e dentes de bocas que já não sorriem mais - tudo são provas, garantias de que um dia houve um passado, uma casa, uma tarde de sol, uma pessoa, um beijo.*

O que sobram são os vestígios aos quais o narrador vai se agarrar para não deixar que as lembranças se desvaneçam para sempre: "Eu, que já tenho tão pouco... Eu o guardião daquelas tardes extintas".* A matéria do romance são os rastros: objetos insignificantes que permitem agora reconstituir momentos efêmeros e felizes de sua adolescência. A rememoraçáo a partir dos rastros vai evitar o apagamento da memória das férias passadas com sua família e a de Lylia. "Eu posso recordar todas as coisas e gentes de meu passado nos mínimos detalhes. E, na verdade, é só isso que me dá gosto... Recordar."* Como sabemos, a etimologia de recordar e fazer passar novamente pelo coração.

\section{Concluindo}

As obras de Letícia Wierzchowski cuja leitura acabamos de realizar não se limitam a ser uma literatura de imigração ou sobre imigrantes. Trata-se do que se pode chamar de "literatura migrante" ou "literatura da migrância", na qual os dois horizontes culturais o do país de origem e o do país de chegada - são contemplados e onde se podem verificar passagens transculturais, ou seja, quando uma cultura fertiliza a outra, gerando algo de novo que não é mais
* (WIERZCHOWSKI, Letícia. Os Getka. São Paulo: Record, 2010: 10.)

* (Ibidem:11.)

* (Ibidem: 124.) 
* (BENJAMIN, Walter. A imagem de Proust. In__ Magia e técnica, arte e política. Obras escolhidas, vol, I. São Paulo: Brasiliense, 1994: 37.)

* (WIERZCHOWSKI, Letícia. Uma ponte para Terebin. Rio de Janeiro: Record, 2006: 426.) totalmente polonês nem ainda inteiramente brasileiro. Nesse sentido, sua obra aproxima-se da de Moacyr Scliar, cujos personagens transitam de uma paisagem cultural a outra e onde a memória atua no sentido benjaminiano: através da lembrança, os fatos vividos no passado são (re)significados no presente, produzindo um novo sentido. A rememoração associa-se à constituição da subjetividade.

$\mathrm{Na}$ verdade seus romances comprovam a importância de rememorar as vivências de seus ancestrais, já que essas lembranças iluminam o presente da narradora que reavalia a herança cultural e afetiva recebida de seus antepassados para melhor poder situar-se no tempo presente. Citando uma vez mais Benjamin:

um acontecimento vivido é finito, ou pelo menos encerrado na esfera do vivido, ao passo que o acontecimento lembrado é sem limites, porque é apenas uma chave para tudo o que veio antes e depois.*

À página 426, na fala da fotografia do bisavô que nunca veio ao Brasil, se lê: "Tudo aqui nestas páginas faz parte de um mundo que se acabou".*Na perspectiva benjaminiana, findaram os acontecimentos vividos que são finitos. Contudo, sua representação nesse romance memorial transforma-os em acontecimentos lembrados os quais não têm limites.

Com essas obras, a autora inaugura a diversidade da cultura polonesa na literatura sul-rio-grandense e brasileira e inscreve esse elemento também como componente da "gauchidade", esgarçando salutarmente tal conceito no sentido da relação e da alteridade.

Zilá Bernd é professora titular aposentada do Instituto de Letras da UFRGS. É docente permanente do PPG-Letras/UFRGS e do Mestrado em Memória Social e Bens Culturais do Unilasalle/Canoas-RS. É doutora em Letras pela USP com pós-doutorado na Université de Montreal, em Literatura Comparada. É editora da Revista Interfaces Brasil-Canadá e presidente pro tempore da Abecan (2012-2013). Tem Bolsa PQ do CNPq. Publicou o Dicionário de mobilidades culturais; percursos americanos (Literalis, 2010) e Tributo a Moacyr Scliar (PUCRS, 2012), em colaboração com Maria Eunice Moreira e Ana Maria L. de Mello. E-mail: <zilabster@gmail.com> 